4. Böyum, A.: A one-stage procedure for isolation of granulocytes and lymphocytes from human blood. Scand. J. Clin. Lab. Invest. (Suppl. 97), 21: 51 (1968).

5. Carr, M. C., Stites, D. P., and Fudenberg, H. H.: Cellular immune aspects of the human fetal-maternal relationship. 1 . In vitro response of cord blood lymphocytes to phytohemagglutinin. Cell. Immunol., 5: 21 (1972).

6. Faulk, W. P., Goodman, J. R., Maloney, M. A., et al.: Morphology and nucleoside incorporation of human neonatal lymphocytes. Cell. Immunol. 8: 166 (1973).

7. Fowler, R., Jr., Schubert, W. K., and West, C. D.: Acquired partial tolerance to homologous skin grafts in the human infant at birth. Ann. N. Y. Acad. Sci., 87: 403 (1960).

8. Hedeskov, C. J., and Esmann, V.: Respiration and glycolysis of normal human lymphocytes. Blood, 28: 163 (1966).

9. Hedeskov, C. J., and Esmann, V.: Major metabolic pathways of glucose in normal human lymphocytes and the effect of cortisol. Biochim. Biophys. Acta, 148: 372 (1967).

10. Hohorst, H. J.: L-(+)-Lactate: Determination with lactic dehydrogenase and DPN. In: H. U. Bergmeyer: Methods of Enzymatic Analysis, p. 266 (Academic Press, Inc., New York, 1963).

11. Klein, R. B., Rich, K. C., Biberstein, M., et al.: Defective mononuclear and neutrophilic phagocyte chemotaxis in the newborn. Clin. Res., 24: 180A (1976).

12. Lawton, A. R., Self, K. S., Royal, S. A., et al.: Ontogeny of B-lymphocytes in the human fetus. Clin. Immunol. Immunopathol., 1: 84 (1972).

13. Leikin, S., Mochir-Fatemi, F., and Park, K.: Blast transformation of lymphocytes from newborn human infants. J. Pediat., 72: 510 (1968).

14. Leikin, S., Whang-Peng, J., and Oppenheim, J. J.: In vitro transformation of human cord blood lymphocytes by antigens. In: Proceedings of the Fifth Leukocyte Culture Conference, p. 389 (Academic Press, New York, 1970).

15. McConnachie, P. R., Rachelefsky, G., Stiehm, E. R., et al.: Antibody dependent lymphocyte killer function and age. Pediatrics, 52: 795 (1973).

16. Metcoff, J., Yoshida, T., Morales, M., et al.: Biomolecular studies of fetal malnutrition in maternal leukocytes. Pediatrics, 47: 180 (1971).

17. Naiman, J. L., Punnett, H. H., Lischner, H. W., et al.: Possible graft-versushost reaction after intrauterine transfusion for Rh erythroblastosis. N. Engl. J. Med., 281: 697 (1969).

18. Pachman, L. M.: The carbohydrate metabolism and respiration of isolated small lymphocytes. In vitro studies of normal and phytohemagglutinin stimulated cells. Blood, 30: 691 (1967).
19. Parkman, R., Mosier, D., Umansky, 1., et al.: Graft-versus-host disease after intrauterine ane exchange transfusions for hemolytic disease of the newborn. N. Engl. J. Med., 290: 359 (1974).

20. Roos, D., and Loos, J. A.: Changes in the carbohydrate metabolism of mitogenically stimulated human peripheral lymphocytes. Biochim. Biophys. Acta, 222: 565 (1970).

21. Roos, D., de Boer, J. E. G., Huismans, L., et al.: Dose-response of lymphocyte carbohydrate metabolism to phytohekiagglutinin. Exp. Cell. Res., 75: 185 (1972).

22. Schneider, W., Pappas, A., and Scheurlen, P. G.: Hexokinase-inhibition and lymphocyte transformation. Klin. Wschr., 50: 261 (1972).

23. Slein, M. W.: D-Glucose. Determination with hexokinase and glucose-6phosphate dehydrogenase. In H. U. Bergmeyer: Methods of Enzymatic Analysis, p. 117 (Academic Press, Inc., New York, 1963).

24. St. John, J. B.: Determination of ATP in Chlorella with the luciferin-luciferase enzyme system. Anal. Biochem., 37: 409 (1970).

25. Uhr, J. W., Dancis, J., and Newmann, C. G.: Delayed-type hypersensitivity in premature neonatal humans. Nature, 187: 1130 (1960).

26. Warwick, W. J., Good, R. A., and Smith, R. T.: Failure of passive transfer of delayed hypersensitivity in the newborn human infant. J. Lab. Clin. Med., 56: 139 (1960).

27. Wybran, J., Carr, M. C., and Fudenberg, H. H.: The human rosette-forming cell as a marker of a population of thymus-derived cells. J. Clin. Invest., 51 : 2537 (1971).

28. Yoshida, T., Metcoff, J., Morales, M., et al.: Human fetal growth retardation. II. Energy metabolism in leukocytes. Pediatrics, 50: 559 (1972).

29. Sigma Chemical Co., St. Louis, Mo.

30. Boehringer Mannheim Corp., San Francisco, Calif.

31. Burroughs Wellcome Co., Burlingame, Calif

32. The excellent technical assistance of $\mathrm{Mr}$. Theodore Henderson is greatly appreciated. We are also indebted to Ms. Mary Forest and Ms. Micheline Chamberlain for assistance in the preparation of this manuscript.

33. This research was supported in part by Grants RR 5354 and CA 12800 from the United States Public Health Service and by the Karen Brigham Memorial Fund.

34. Requests for reprints should be addressed to: S. A. Feig, M. D., Department of Pediatrics, UCLA School of Medicine, Los Angeles, Calif. 90024 (USA).

35. Received for publication December 6, 1976

36. Accepted for publication March 2, 1977
Amniotic fluid arylsulfatase A electrophoresis enzymoimmunodiffusion enzymoimmunoelectrophoresis isozymes

metachromatic leukodystrophy prenatal diagnosis sulfatide lipidosis

\title{
Prenatal Diagnosis of Metachromatic Leukodystrophy by Electrophoretic and Immunologic Techniques
}

\author{
MARIO C. RATTAZZI(49) AND RONALD G. DAVIDSON
}

Division of Human Genetics, Department of Pediatrics at Children's Hospital, State University of New York at Buffalo, Buffalo, New York, USA, and Department of Pediatrics, McMaster University Medical Centre, Hamilton, Ontario, Canada

\section{Summary}

Electrophoretic examination of extracts of cultured amniotic fluid cells from a pregnancy at risk for metachromatic leukodystrophy (MLD) showed absence of arylsulfatase A (AS-A) activity. Immunodiffusion with anti-human AS-A immune serum failed to show enzymatically active arcs of immune precipitate. Electrophoretic studies and quantitative assay of extracts of organs from the aborted fetus confirmed the diagnosis of MLD. Electrophoresis of amniotic fluid from this and one additional fetus with MLD showed an arylsulfatase pattern qualitatively and quantitatively indistinguishable from normal. In both normal and MLD fluids, the AS-A band was replaced by a band with lower anodal mobility. Only the anodal band of normal amniotic fluid, however, reacted with the anti-AS-A immune serum in immunoelectrophoresis. Assay of amniotic fluid with $p$ nitrocatechol sulfate (PNCS) as a substrate showed marked deficiency of "AS-A" activity in the fluids from the two MLD pregnancies.

An optimal procedure for prenatal detection of MLD should 
include electrophoresis of extracts of cultured amniotic fluid cells with visual demonstration of absence of AS-A activity. Immunologic techniques applied to cell-free amniotic fluid may be of help in the rapid identification of the fetal genotypes.

\section{Speculation}

Qualitative methods such as electrophoresis and immunodiffusion allow reliable prenatal diagnosis of metachromatic leukodystrophy using cultured amniotic fluid cells. The peculiarities of arylsulfatase in amniotic fluid render this material less suitable for prenatal diagnosis, but may provide an insight in the structural and functional defect of arylsulfatase $A$ in this disease.

Metachromatic leukodystrophy (MLD; sulfatide lipidosis) comprises a group of inherited degenerative diseases of the nervous system, characterized by demyelination and accumulation of cerebroside sulfates (sulfatides) in nervous system tissues and visceral organs $(1,42)$. Deficient activity of the lysosomal enzyme, arylsulfatase A (AS-A; EC. 3.1.6.1) can be demonstrated in this disorder using synthetic chromogenic or fluorogenic substrates $(1,32)$. This reflects a deficient activity of cerebroside sulfate sulfatase (22), which leads to accumulation of undegraded sulfatides. MLD is clinically and biochemically heterogeneous and a number of clinical types of MLD have been demonstrated, three of which are arbitrarily named late infantile, juvenile, and adult, on the basis of age of onset. All of these variants are transmitted as autosomal recessive traits and, in spite of the variation in clinical manifestations, have equally profound deficiencies of AS-A activity $(16,28,32)$. Recently, two cases of the late infantile form of MLD have been reported with partial deficiency of AS-A $(9,25)$. In mucosulfatidosis, a neurodegenerative disease clinically similar to the late infantile type of MLD, there is additional deficiency of lysosomal arylsulfatase $B(A S-B)$ and of arylsulfatase $C$ (AS-C), a microsomal enzyme (23). Finally, in another lysosomal storage disease, mucopolysaccharidosis type VI (MPS VI; Maroteaux-Lamy syndrome), deficiency of AS-B occurs (37).

The structural and functional relationships among the three isozymes of arylsulfatase are only partially understood. In particular, the two lysosomal forms, AS-A and AS-B, differ in molecular weight, subunit composition, isoelectric point, and antigenic properties $(13,26,34)$. The chemical nature of the compounds stored or excreted in MLD and MPS VI $(1,37)$ and in vitro enzymatic studies $(14,21)$ strongly suggests that sulfatides are natural substrates for AS-A, and that $N$-acetyl galactosamine-4sulfate residues in chondroitin and dermatan sulfate are natural substrates for AS-B. Both enzymes recognize PNCS as substrate in vitro, but the activity of AS-B towards PNCS is inhibited by sodium pyrophosphate and sodium chloride; this is the basis of an indirect assay system commonly used to measure AS-A activity in the presence of AS-B (5). This method has been used in the recent past for prenatal diagnosis of MLD, utilizing cultured amniotic fluid cells and cell-free amniotic fluid $(8,15,19,24$, $39,41)$. In the six cases reported, there has been a considerable and worrisome variability in the results of the quantitative assays, which might be avoided by a more direct, qualitative demonstration of AS-A activity. This report describes a prenatal diagnosis of the late infantile form of MLD based on the demonstration of absent AS-A activity in cultured amniotic fluid cells by cellulose acetate gel electrophoresis (32), and by immunologic methods (30); and some characteristics of a new arylsulfatase isozyme detected in cell-free amniotic fluid.

\section{CASE HISTORY}

A 2.5-year-old white female was admitted to the Buffalo Children's Hospital with the typical clinical findings of MLD. Her development had been apparently normal until approximately 1 year of age when she was first noted to have difficulty with walking. At the time of admission she had been unable to walk for about 3 months, was noted to tremble during purposeful movements, and kept her legs extended and her toes pointed while in the prone position. Her deep tendon reflexes were decreased to absent. Initial laboratory findings were unremarkable except for a cerebrospinal fluid protein of $402 \mathrm{mg} / 100 \mathrm{ml}$. A urine specimen was positive for metachromatic granules and a sural nerve biopsy revealed the typical metachromasia. The diagnosis of MLD was confirmed using cellulose acetate gel electrophoresis of extracts of the patient's leukocytes and cultured skin fibroblasts $(30,32)$; no AS-A activity was seen. Both parents showed reduction of AS-A activity, as expected in heterozygotes (18).

The child was the product of her parent's first pregnancy. The mother was 27 years of age at the time and the father 30 . When the patient was admitted, the mother was already pregnant. After appropriate counseling the parents decided to have the pregnancy monitored and amniocentesis was performed at approximately 15 weeks of gestation. On the basis of the results of subsequent biochemical studies on cultured amniotic fluid cells, the parents decided to terminate the pregnancy and a female fetus of approximately 19 weeks of gestational age was delivered by hysterotomy. Tissue specimens were immediately processed for biochemical and histologic studies and the remaining tissues were frozen at $-60^{\circ}$ for further studies.

\section{MATERIALS AND METHODS}

\section{FETAL CELLS AND TISSUES}

Amniotic fluid cells obtained by amniocentesis were cultured as previously described (12). Control cell culture samples known to be chromosomally normal were obtained from pregnancies monitored previously for chromosomal abnormalities. Refrigerated or fresh residual cell-free amniotic fluids from these and similar cases were centrifuged at $20,000 \times g$ for $30 \mathrm{~min}$ at $4^{\circ}$ to remove cellular debris, and either concentrated by ultrafiltration and analyzed immediately, or stored at $-20^{\circ}$. Fetal organs and placental tissue utilized as controls were from two normal pregnancies terminated at about 20 weeks for nontherapeutic reasons.

\section{PREPARATION OF SAMPLES}

Cell extracts were prepared by ultrasonic disruption of a suspension $(1: 5 \mathrm{v} / \mathrm{v})$ of saline-washed cells in $0.05 \mathrm{M}$ sodium acetate buffer, $\mathrm{pH} 6.5$, containing $0.1 \%$ bovine serum albumin and $1 \mathrm{mM} \beta$-mercaptoethanol. The lysate was incubated at $25^{\circ}$ for $30 \mathrm{~min}$ then centrifuged at $40,000 \times \mathrm{g}$ for $30 \mathrm{~min}$ at $4^{\circ}$ to precipitate and remove the microsomal AS-C. Tissue extracts were prepared by mincing in distilled water $(1: 5 \mathrm{v} / \mathrm{v})$, sonication at $4^{\circ}$, and centrifugation as above. One-tenth volume of $0.5 \mathrm{M}$ acetate buffer, $\mathrm{pH} 5.0$, was added to the supernatant, followed by incubation at $25^{\circ}$ and recentrifugation (32). Supernatants from high speed centrifugation were used for arylsulfatase assay and electrophoresis.

\section{ELECTROPHORESIS}

Electrophoresis was performed on sheets of cellulose acetate gel ("Cellogel") (43), using $0.036 \mathrm{M}$ sodium barbital-0.037 $\mathrm{M}$ sodium acetate-acetic acid buffer, $\mathrm{pH} 7.0$, containing $1 \mathrm{mM} \beta$ mercaptoethanol and $0.01 \%$ sodium azide (32). Prior to electrophoresis, the gels were equilibrated overnight in buffer containing $0.05 \%$ bovine serum albumin. Samples of organ or cell extracts $(10-20 \mu \mathrm{l})$ were pipetted onto the gel as thin bands $15-$ $20 \mathrm{~mm}$ long and a constant current of $10 \mathrm{~mA}, 150 \mathrm{~V}$ was applied for $3.5 \mathrm{hr}$ at room temperature. Gels were developed with substrate solution containing $3 \mathrm{mg} / \mathrm{ml}$ of 4 -methyl umbelliferyl sulfate (4-MUS), potassium salt (32), in $0.5 \mathrm{M}$ sodium acetateacetic acid buffer, pH 5.6, followed by incubation at $37^{\circ}$ in a 
moist chamber. The fluorescence of the bands was enhanced by placing the gel, porous face down, in $10 \%$ formalin for $4 \mathrm{~min}$ and then in $0.25 \mathrm{M}$ sodium carbonate-glycine buffer, $\mathrm{pH} 10$, for $4 \mathrm{~min}$. Fluorescent bands of enzyme activity were observed under long wave $(365 \mathrm{~nm})$ ultraviolet light (32).

\section{IMMUNOLOGIC TECHNIQUES}

Antisera were raised in rabbits following standard immunization procedures (2), using as antigen AS-A partially purified from human term placenta. Isolation of AS-A was obtained by the autolysis-cold acetone precipitation procedure of GniotSzulzycka and Komoszynsky (11), followed by lyophilization and preparative electrophoresis on Pevikon (44) blocks at $4^{\circ}$ in barbital-acetate buffer as above. Absence of AS-B in the eluted AS-A was assessed by analytic electrophoresis on Cellogel. As also shown by others $(26,33)$, the anti-AS-A immune serum thus obtained did not cross-react with AS-B (3).

Immunoelectrophoresis and immunodiffusion were carried out on Cellogel (30). After diffusion of the reactants and washing, the gels were developed for enzymatic activity as described above. Immune complexes of AS-A with anti-AS-A antibodies retain enzymatic activity with PNCS (26) and with the fluorogenic substrate, 4-MUS (3); thus, the oligospecific antiserum could be used to detect specifically AS-A immune complexes by their enzymatic activity.

\section{QUANTITATIVE ASSAYS}

AS-A activity was measured with PNCS (45), according to the method of Baum et al. (5). Proteins were measured spectrophotometrically at $215-225 \mathrm{~nm}(40)$.

\section{RESULTS}

As shown in Figure 1, the clinical and histochemical diagnosis of MLD in the patient could be confirmed reliably by direct examination of the fluorescent bands of arylsulfatase activity after electrophoresis and development with the fluorogenic substrate, 4-MUS. The leukocyte extract from the patient with MLD showed no detectable AS-A activity and as expected,

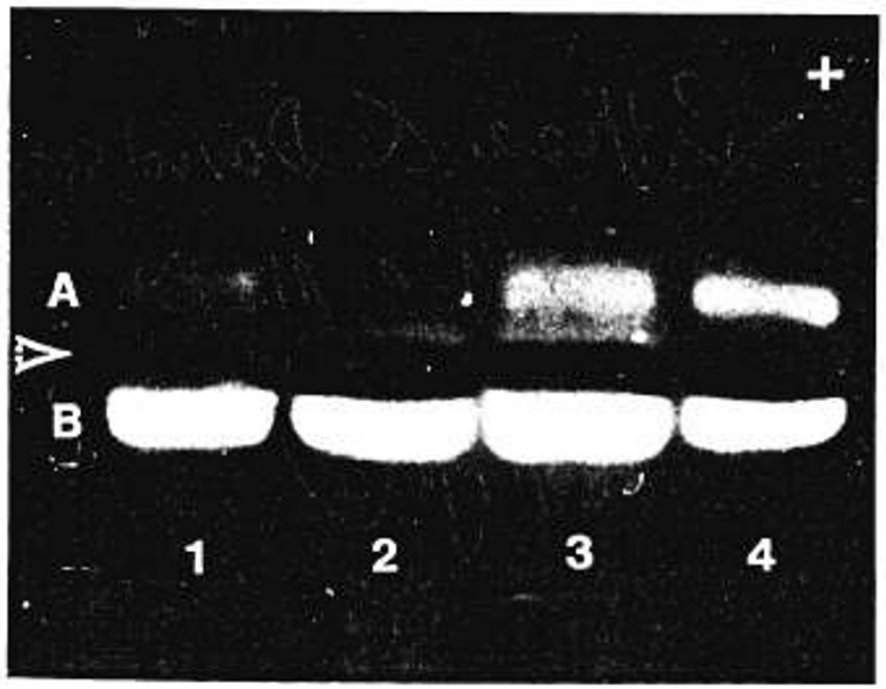

Fig. 1. Fluorescent bands of arylsulfatase activity after electrophoresis of leukocyte extracts on cellulose acetate gel at $\mathrm{pH} 7.0$ and development with the fluorogenic substrate, 4-methyl umbelliferyl sulfate. Lane 1, mother of patient; lane 2, patient with metachromatic leukodystrophy; lane 3, father of patient; lane 4, normal individual. Note the absence of arylsulfatase $A$ (band $(A)$ in lane 2 , and its decreased fluorescence, relative to that of arylsulfatase $B$ and (B) in both parents. The dark band between AS-A and AS-B is hemoglobin. Arrow = point of application. there was a decrease of AS-A activity, relative to AS-B, in the parents.

Electrophoretic examination of extracts of cultured amniotic fluid cells from the pregnancy at risk for MLD also showed absence of AS-A activity (Fig. $2 a$ ). This result was confirmed by immunologic methods: immunodiffusion of extracts of cultured amniotic fluid cells with anti-human AS-A immune serum failed to show an enzymatically active arc of immune precipitate attributable to AS-A in the sample (Fig. 3). After termination of the pregnancy, the diagnosis of MLD in the fetus was confirmed
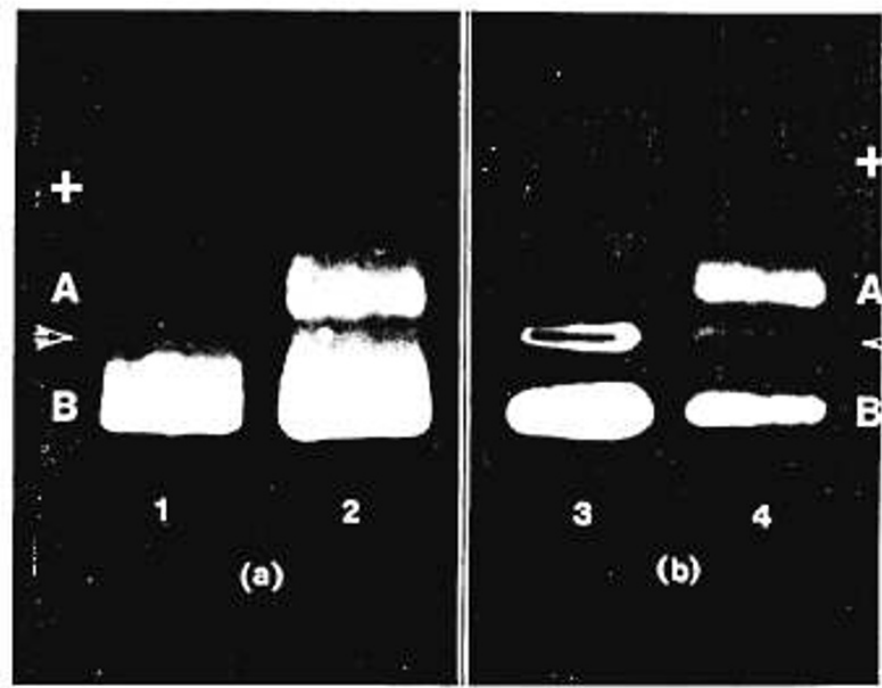

Fig. 2. Composite picture of electropherograms of amniotic fluid cell extracts, $(a)$, and fetal liver extracts, $(b)$. Notice the absence of arylsulfatase A activity in cultured amniotic fluid cells from fetus at risk for metachromatic leukodystrophy (lane 1) and in liver tissue from the same fetus (lane 3). Control cultured amniotic fluid cells (lane 2) and fetal liver (lane 4) show normal AS-A band. The fluorescent bands at the point of application (arrow) in lanes 3 and 4 are due to AS-C incompletely removed by the acid precipitation procedure (see "Materials and Methods").

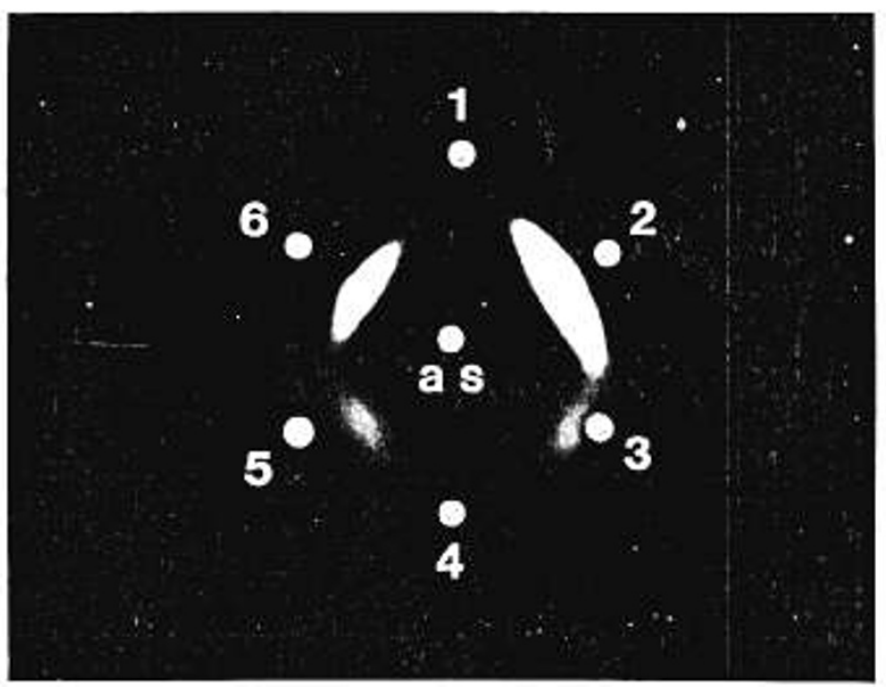

Fig. 3. Enzymatically active arcs of immunoprecipitate after double immunodiffusion on Cellogel with anti-human AS-A (center well, a s), and staining with fluorogenic substrate. Amniotic fluid cell extracts from normal pregnancies (wells 2 and 6) show strong reaction, whereas the cell extract from the pregnancy at risk for metachromatic leukodystrophy (well 1) shows no reaction. The samples had approximately the same protein concentration. The reaction of diluted, partially purified AS-A (wells 3 and 5) and the absence of reaction of 5-fold more concentrated partially purified AS-B (well 4) are also visible. 
lectrophoretically by showing absence of AS-A activity in exracts of fetal liver (Fig. $2 b$ ), other fetal organs and placenta ssing as controls tissues from fetuses of similar gestational age. $n$ addition, microscopic examination of sections of brain and sidney showed metachromatic granules of sulfatide in the fetal :ells.

Assay of AS-A activity in fetal organs using the conventional ?NCS assay (5) also showed a profound deficiency of AS-A in he affected fetus (Table 1). Minimal activity was detected only $\mathrm{n}$ extracts of kidney and adrenal glands (2.3-8.5\% and 0.92$1.5 \%$ of controls, respectively). The relatively low AS-A activity $\mathrm{n}$ normal brain and kidney (Table 1 ) has also been noted by thers $(1,41)$.

Concentrated (20- to 30 -fold), cell-free amniotic fluids were Ilso examined by electrophoresis to determine whether this naterial could be used for prenatal diagnosis of MLD. Figure 4 shows the results of the electrophoresis of amniotic fluid from the fetus with MLD, from a pregnancy in which MLD had been tiagnosed by another laboratory, and from a control. The electrophoretic pattern of arylsulfatase in affected pregnancies was qualitatively and quantitatively indistinguishable from that of cormal amniotic fluid; that is, in both normal and MLD fluids, the AS-A band was replaced by a band with lower anodal mobility. This enzyme form was antigenically related to AS-A since, in the normal fluids, it reacted with anti-AS-A immune

Table 1. Arylsulfatase $A$ activity (nanomoles substrate cleaved per hr per $\mathrm{mg}$ protein) in extracts of fetal organs assayed at pH 5.0 with p-nitrocatechol sulfate as substrate (5) ${ }^{1}$

\begin{tabular}{lccc}
\hline \multicolumn{1}{c}{ Organ } & \multicolumn{3}{c}{ Fetus with MLD Fetus control 1 Fetus control 2 } \\
\hline Placenta & NDet. & 345.96 & 165.97 \\
Liver & NDet. & 338.15 & 460.98 \\
Brain & NDet. & $11.91^{*}$ & $28.80^{*}$ \\
Cerebellum & NDet. & 10.64 & $17.27^{*}$ \\
Kidney & 1.02 & 44.70 & 12.00 \\
Adrenal glands & 1.44 & 155.73 & 95.85 \\
\hline
\end{tabular}

'MLD: metachromatic leukodystrophy; NDet.: not detectable. Unless otherwise noted ("), each value is the average of two separate assays.

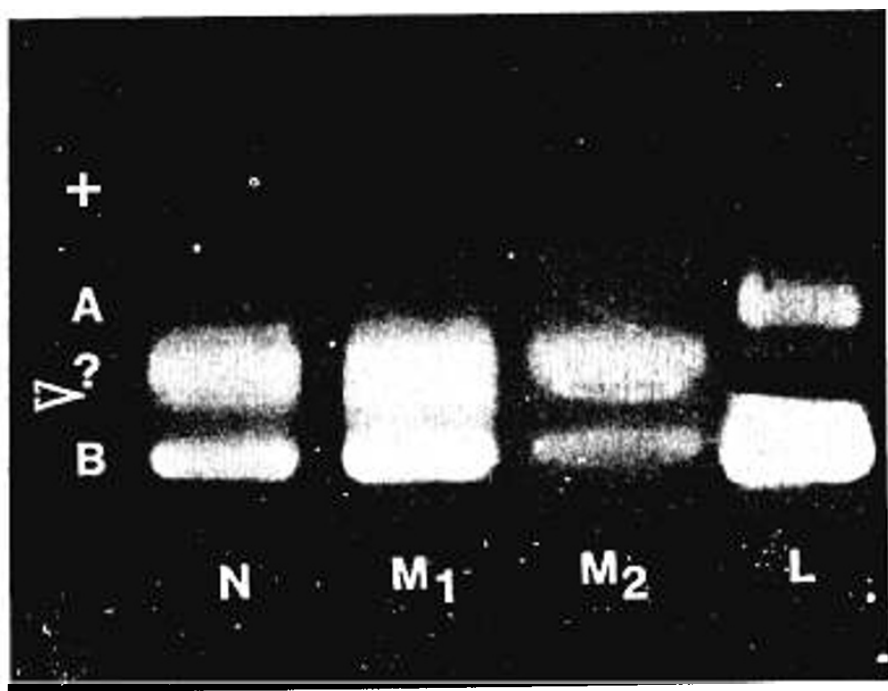

Fig. 4. Electrophoresis of concentrated amniotic fluids from a normal pregnancy (lane $\mathrm{N}$ ), from two pregnancies in which the fetus had metachromatic leukodystrophy (MDL) (lanes $\mathrm{M}_{1}$ and $\mathrm{M}_{2}$ ) and of an extract of normal leukocytes (lane $L$ ). The difference in electrophoretic mobility between the AS-A band (A) in lane L and the band marked "?" in all amniotic fluids is evident, as is the normal activity of this band in the MLD pregnancy fluids, $M_{1}$ and $M_{2}$. Sample $M_{1}$ is from the pregnancy reported in this work. serum in immunoelectrophoresis (Fig. 5). In the MLD amniotic fluids, however, no enzymatically active arcs of immune precipitate were formed after reaction with this antiserum (Fig. 6).

In contrast to the apparently normal enzyme activity of all

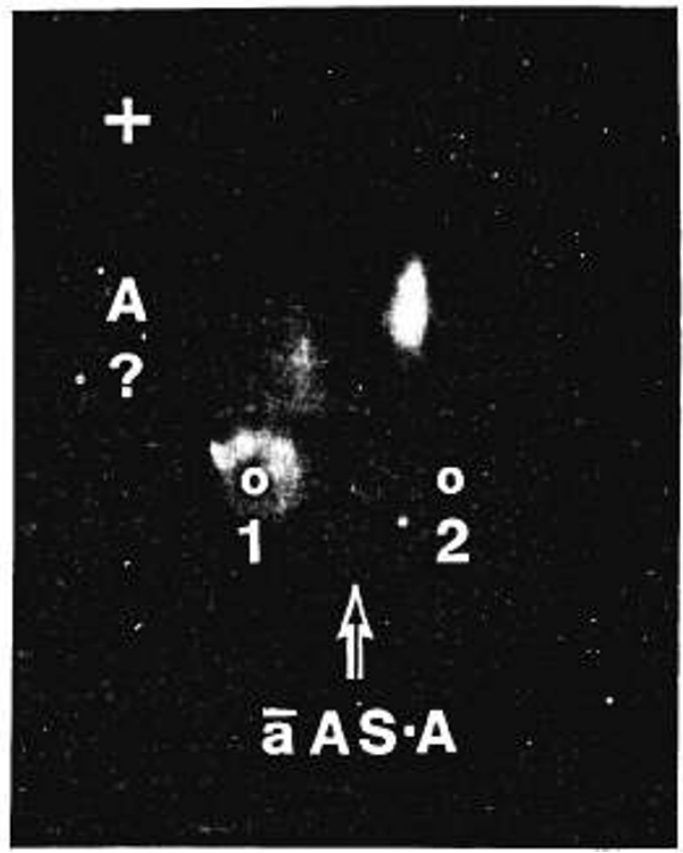

Fig. 5. Enzymatically active arcs of immunoprecipitate detected with fluorogenic substrate after electrophoresis on Cellogel and immunodiffusion with anti-human AS-A serum (āAS·A), which was applied as a line (arrow) between the two samples. The arc of reaction given by sample 1 , a concentrated, normal amniotic fluid, is clearly in a different position than that given by sample 2 , a normal fibroblast extract. This corresponds to the relative mobilities of the anodal bands shown in Figure 4. The ring of enzyme activity around the application point 1 is due to AS-B precipitated as a result of the concentration procedure and incompletely removed by washing the gel.

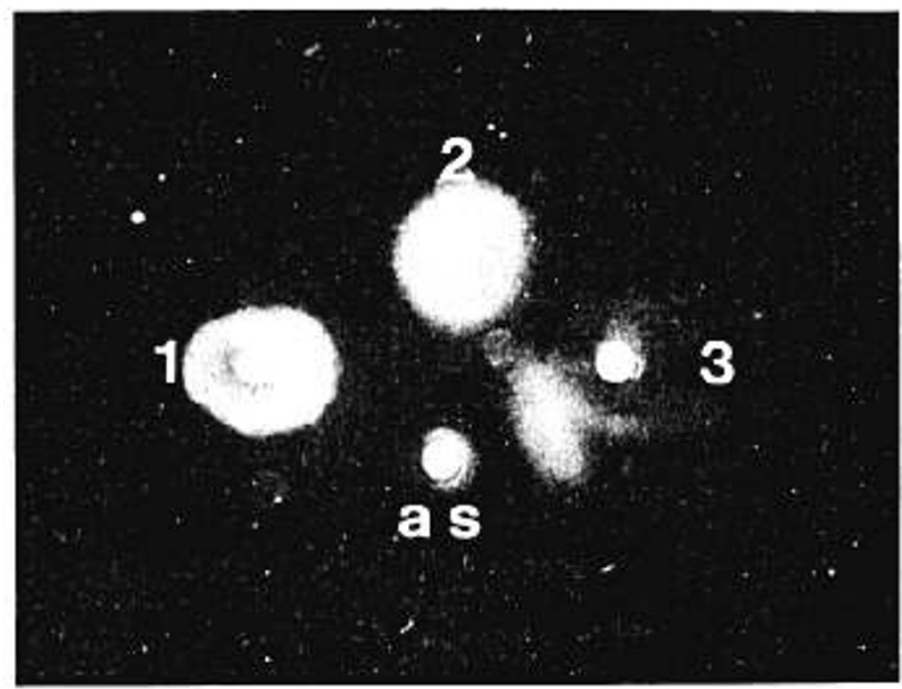

Fig. 6. Double immunodiffusion of concentrated amniotic fluids (wells 1,2 , and 3) against anti-human AS-A serum (well a s), after incubation with fluorogenic substrate. An enzymatically active arc of immunoprecipitate is present in correspondence with well 3 , containing normal amniotic fluid, but not in correspondence with wells 1 and 2, containing amniotic fluids from fetuses with metachromatic leukodystrophy. The rings of enzyme activity around the wells are due to AS-B precipitated as a result of the concentration procedure. 
bands using 4-MUS as substrate, duplicate assays of amniotic fluids with PNCS as substrate (5) showed a marked deficiency of "AS-A" activity in the fluids from the two MLD pregnancies as compared to four fluids from normal pregnancies $(0-0.065 \mathrm{nmol}$ PNCS cleaved $/ \mathrm{hr} / \mathrm{mg}$ protein against $0.31-1.58 \mathrm{nmol} / \mathrm{hr} / \mathrm{mg}$ ).

No clues as to the origin of the arylsulfatase band with lower anodal mobility, apparently unique to amniotic fluid, and detected in 20 additional samples of amniotic fluid from pregnancies not at risk for MLD, could be obtained by either incubation at $37^{\circ}$ of cell homogenates prepared in normal amniotic fluid, or by adjusting the $\mathrm{pH}$ of the amniotic fluid to that of cell extracts by dialysis against the appropriate buffer. These procedures did not alter the mobility of cellular AS-A or of the amniotic fluid arylsulfatase band, respectively. In addition, absence of activity after incubation of electrophoretic gels with 4-MUS at $\mathrm{pH} 7$ showed that the band was not due to AS-C, which reacts readily at this $\mathrm{pH}(32)$.

\section{DISCUSSION}

The first prenatal diagnosis of MLD was reported in 1970 by Nadler and Gerbie (24). AS-A activity with PNCS was measured in cultured amniotic fluid cells from a pregnancy at risk and was found to be less than $10 \%$ of that observed in cultured amniotic fluid cells from control subjects. The pregnancy was terminated and the diagnosis confirmed by assay of AS-A activity in the liver of the fetus. Subsequently, five additional diagnoses have been reported $(8,15,19,39,41)$, four of which were based on the quantitative determination of AS-A activity in cultured amniotic fluid cells, and one (15) on assay of amniotic fluid. In each case, confirmation of the diagnosis in the aborted fetus was obtained biochemically and/or through the demonstration of increased quantities of metachromatic material and/or cerebroside sulfate in brain and other tissues.

This report describes the first prenatal detection of MLD based on electrophoresis of arylsulfatases in cultured amniotic fluid cells. Confirmation of absence of AS-A activity in these cells was also obtained by immunologic techniques, taking advantage of the observation that the formation of the antigenantibody complex does not interfere with the activity of the enzyme towards chromogenic (26) or fluorogenic substrates (3) In fact, there are data to suggest that the complex of AS-A with antibody results in apparent increased enzymatic activity with PNCS (26). Other investigators (38) have reported the presence of an antigenically cross-reacting, enzymatically inactive, AS-A protein in MLD, and Shapira and Nadler (33) have shown recently that this mutant enzyme does not retain any residual enzymatic activity. The detection of immune precipitates by enzymatic assay used in our work would not reveal the presence of inactive immune complexes; although it does not establish that enzymatically inactive cross-reacting material is present in the sample, it is not affected by the presence of such material.

The application to prenatal diagnosis of qualitative electrophoretic and immunologic techniques aimed at the direct demonstration of AS-A was undertaken because of widespread concern over the accuracy of the quantitative assay. The conventional assay using the chromogenic substrate, PNCS, depends on the assumption that the inhibition of AS-B activity in the presence of sodium pyrophosphate and sodium chloride (5) is complete. Under these assay conditions, residual AS-A activity in the range of $3.3-14.5 \%$ of normal control subjects has been found in various tissues $(4,28)$, urine $(36)$, and serum $(6)$ of patients with MLD. This measurable amount of AS-A activity is worrisome because it had been noted that AS-A activity in cultured amniotic fluid cells from normal fetuses was only 30 $45 \%$ of the mean levels observed in cultured skin fibroblasts of normal infants and adults (18). These low levels raised the possibility that a heterozygous fetus might not be distinguishable from an affected fetus on the basis of enzyme activity observed in cultured amniotic fluid cells, and led us to use a sensitive electrophoretic method previously employed to demonstrate directly the absence of AS-A activity in late infantile and juvenile MLD (32).

Furthermore, the concern that the "residual AS-A activity" in MLD might in fact be due to incompletely inhibited AS-B, raised by Porter et al. (29), has recently received experimental support from the work of Shapira and Nadler (33), who showed that the "residual AS-A activity" can be removed by immunoabsorption of AS-B. Furthermore, the same investigators have shown that purified AS-B retains about $3 \%$ of its normal activity in the conventional AS-A assay using PNCS (35). Thus, separation of AS-A and AS-B, followed by enzymatic assay, although technically more complex, appears to be more reliable than the indirect inhibition assay method.

The use of cell-free amniotic fluid can help in the diagnosis of lysosomal disorders $(10,17,20,27,31)$, including MLD (8). The assay of AS-A in this material by the indirect PNCS method of Baum et al. (5), however, is open to the same criticisms discussed above, as shown by the data by Wiesman $e t$ al. (41), who found only a $50 \%$ reduction of AS-A activity in amniotic fluid from a fetus with MLD, after assay with PNCS at $\mathrm{pH} 5.0$ and $\mathrm{pH}$ 6.0. In addition, our data indicate that the arylsulfatase band with low anodal mobility characteristic of amniotic fluid is not identical with AS-A from cells, and may not behave exactly as tissue AS-A in the PNCS assay of Baum et al. (5). That a structural relationship with AS-A exists is shown by the immunologic reactivity of the arylsulfatase from normal amniotic fluids with anti-AS-A immune serum; by the absence of immunologic reactivity (or formation of enzymatically inactive immune complexes) of the arylsulfatase from fluids derived from MLD fetuses, in which AS-A is defective; and, indirectly, by the marked deficiency of "AS-A" activity measured with PNCS in fluids from fetuses with MLD found by us and by other investigators $(8,15)$. The apparently normal activity with 4-MUS of the amniotic fluid arylsulfatase band in MLD pregnancies and its electrophoretic mobility in normal and MLD fluids, however, suggest the existence of structural or conformational differences with AS-A from cells.

To account for the difference in electrophoretic mobility between this band and AS-A from cultured amniotic fluid cells, fibroblasts, leukocytes, and tissues, we propose that in amniotic fluid, active subunits of AS-A (34) may form heteropolymers with a less negatively charged moiety. In order to account for the enzymatic activity of the electrophoretic band in amniotic fluid from MLD fetuses, we propose further that the mutant AS-A subunits are somehow stabilized when combined with the moiety in the amniotic fluid, retaining activity with the artificial fluorogenic substrate. However, the antigenic site(s) of the mutant subunit may be altered, and thus not recognized by the antibody to normal AS-A. Alternatively, the structural alteration may result in the formation of inactive immune complexes.

In conclusion, it seems reasonable to recommend that if measurement of AS-A activity with radioactive sulfatide (7) is not feasible, an optimal procedure for the prenatal detection of MLD should include electrophoresis of extracts of cultured amniotic fluid cells with visual demonstration of absence of AS-A activity. In addition, it is possible that application of immunologic techniques to cell-free amniotic fluid may be of help in the rapid identification of the fetal genotypes, but additional cases will have to be examined to confirm the reliability of this approach. Finally, further study of the amniotic fluid arylsulfatase form may provide data on the nature of the arylsulfatase isozymes and of the biochemical defect in MD.

\section{CONCLUSION}

Metachromatic leukodystrophy was diagnosed by qualitative electrophoretic and immunologic methods in a fetus at risk for the disease, and the diagnosis was confirmed by electrophoretic study and quantitation of AS-A in the tissues of the aborted fetus. A new form of arylsulfatase, apparently replacing AS-A in normal amniotic fluids, was detected by electrophoresis, and 
determined to be immunologically related to AS-A. This form was also present and active with 4-MUS in two amniotic fluids from fetuses with MLD, but it did not give enzymatically active immunoprecipitates with the anti-AS-A serum.

\section{REFERENCES AND NOTES}

1. Austin, J., Armstrong, D., and Shearer, L.: Metachromatic leukodystrophy V. The nature and significance of low sulfatase activity: A controlled study of brain, liver and kidney in four patients with metachromatic leukodystrophy. Arch. Neurol., 13: 593 (1965).

2. Bartholomew, W. R., and Rattazzi, M. C.: Immunochemical characterization of human $\beta$-D-N-acetyl hexosaminidase from normal individuals and patients with Tay-Sachs disease. Int. Arch. Allergy Appl. Immunol., 46: 512 (1974).

3. Bartholomew, W, R., and Rattazzi, M. C.: Unpublished results.

4. Bass, N. H., Witmer, E. J., and Dreifuss, F. E.: A pedigree study of metachromatic leukodystrophy. Neurology, 20: 52 (1970).

5. Baum, H., Dodgson, K. S., and Spencer, B.: The assay of arylsulfatases A and $B$ in human urine. Clin. Chem. Acta, 4: 52 (1970)

6. Beratis, N. G., Aron, A. M., and Hirschhorn, K.: Metachromatic leukodystrophy: Detection in serum. J. Pediat., 83: 824 (1973).

7. Booth, C. W., Chen, K. K., and Nadler, H. L.: Cerebroside sulfatase activity in cultivated human skin fibroblasts and amniotic fluid cells. J. Pediat., 86: 560 (1972).

8. Borresen, A. L., and Van der Hagen, C. B.: Metachromatic leukodystrophy. II. Direct determination of arylsulfatase A activity in amniotic fluid. J. Clin. Genet., 4: 442 (1973).

9. Dubois, G., Turpin, J. C., and Baumann, N.: Arylsulfatase isoenzymes in metachromatic leukodystrophy: Detection of a new variant by electrophoresis. Biomed. Exp. 23: 116 (1975).

10. Friedland, J., Perle, G., Saifer, A., Schneck, L., and Volk, B. W.: Screening for Tay-Sachs disease in utero using amniotic fluid. Proc. Soc. Exp. Biol. Med., 136: 1297 (1971).

11. Gniot-Szulzycka, J., and Komoszynsky, M.: Immunoelectrophoretically homogeneous preparation of arylsulphatase A from human placenta. Acta Biochim. Polon., 17: 185 (1970).

12. Gray, C., Davidson, R. G., and Cohen, M. M.: A simplified technique for the culture of amniotic fluid cells. J. Pediat., 79: 119 (1971)

13. Harinath, B. C., and Robins, E.: Arylsulfatases in human brain: separation, purification and certain properties of the two soluble arylsulfatases. J. Neurochem., 18: 245 (1971).

14. Harzer, K., Stinshoff, K., Mraz, W., and Jatzkewitz, H.: The patterns of arylsulfatases $A$ and $B$ in human normal and metachromatic leukodystrophy tissues and their relationship to the cerebroside sulfatase activity. J. Neurochem., 20: 279 (1973).

15. Harzer, K., Zahn, V., Stengel-Rutkowski, S., and Gley, E. O.: Pränatale Diagnose der metachromatischen Leukodystrophie. Deut. Med. Wschr. 100: 951 (1975).

16. Hirose, G., and Bass, N. H.: Metachromatic leukodystrophy in the adult: A biochemical study. Neurology, 22: 312 (1972).

17. Hujing, F., Warren, R. J., and McLeod, A. G. W.: Elevated activity of lysosomal enzymes in amniotic fluid of the fetus with mucolipidosis (I-cell disease). Clin. Chim. Acta, 44: 453 (1973).

18. Kaback, M. M., and Howell, R. R.: Infantile metachromatic leukodystrophy. Heterozygote detection in skin fibroblasts and possible applications to intrauterine diagnosis. N. Engl. J. Med., 282: 1336 (1970).

19. Leroy, J. C., Van Elsen, A. F., Martin, J. J., Dumon, J. E., Hulet, A. E., Okada, S., and Navarro, C.: Infantile metachromatic leukodystrophy: Confirmation of prenatal diagnosis. N. Engl. J. Med., 288: 1365 (1973).

20. Lowden, J. A., Cutz, E., Cohen, P. E., Rudd, N., and Doran, T. A.: Prenatal diagnosis of $\mathrm{Gm}_{1}$ gangliosidosis. N. Engl. J. Med., 288: 225 (1973).

21. Matalon, R., Arbogast, B., and Dorfman, A.: Deficiency of chondroitin sulfate $\mathrm{N}$-acetyl galactosamine-4-sulfate sulfatase in Maroteaux-Lamy syndrome. Biochem. Biophys. Res. Commun., 61: 1450 (1974).

22. Mehl, E., and Jatzkewitz, H.: Cerebroside 3-sulfate as a physiological substrate of arylsulfatase A. Biochim. Biophys. Acta, 151: 619 (1968).

23. Murphy, J. V., Wolfe, H. J., Balazs, E. A., and Moser, H. W.: A patient with deficiency of arylsulfatase A, B, C and steroid sulfatase, associated with storage of sulfatide, cholesterol sulfate and glycosaminoglycans. In: J. Bernsohn and H. J. Grossman: Lipid Storage Diseases: Enzymatic Defects and
Clinical Implications, p. 67 (Academic Press, New York, 1971).

24. Nadler, H. L., and Gerbie, A. B.: Role of amniocentesis in the intrauterine detection of genetic disorders. N. Engl. J. Med., 282: 596 (1970).

25. Nadler, H. L., and Shapira, E.: Personal communication.

26. Neuwelt, E., Stumpf, D., Austin, J., and Kohler, P.: A monospecific antibody to human sulfatase $A$ : Preparation, characterization and significance. Biochim. Biophys. Acta, 236: 333 (1971).

27. O'Brien, J. S., Okada, S., Fillerup, D., Veath, M. L., Adornato, B., Brenner, P. H., and Leroy, J. G.: Tay-Sachs disease: Prenatal diagnosis. Science, 172: 61 (1971).

28. Percy, A. K., and Kaback, M. M.: Infantile and adult-onset metachromatic leukodystrophy. N. Engl. J. Med., 285: 785 (1971).

29. Porter, M. T., Fluharty, A. L., Trammell, J., and Kihara, H.: A correlation of intracellular cerebroside sulfatase activity in fibroblasts with latency in metachromatic leukodystrophy. Biochem. Biophys. Res. Commun., 44: 660 (1971).

30. Rattazzi, M. C., Carmody, P. J., and Davidson, R. G.: Studies on human lysosomal $\beta$-D-N-acetyl-hexosaminidase and arylsulfatase isozymes. In: $\mathrm{C}$. L. Markert: Isozymes. II. Physiological Function, p. 439 (Academic Press, New York, 1975).

31. Rattazzi, M. C., and Davidson, R. G.: Prenatal detection of Tay-Sachs disease. In: A. Dorfman: Antenatal Diagnosis, p. 207 (University of Chicago Press, Chicago, 1972).

32. Rattazzi, M. C., Marks, J. S., and Davidson, R. G.: Electrophoresis of arylsulfatase from normal individuals and patients with metachromatic leukodystrophy. Amer. J. Hum. Genet., 25: 310 (1973).

33. Shapira, E., and Nadler, H. L.: The nature of the residual arylsulfatase activity in metachromatic leukodystrophy. J. Pediat., 86: 881 (1975).

34. Shapira, E., and Nadler, H. L.: Purification and some properties of soluble human liver arylsulfatases. Arch. Biochem. Biophys., 170: 179 (1975).

35. Shapira, E., and Nadler, H. L.: Problems associated with the determination of arylsulfatase $A$ and $B$ using nitrocatechol sulfate substrate, Clin. Chim. Acta, 65: 1 (1975).

36. Stumpf, D., and Austin, J.: Metachromatic leukodystrophy (MLD). IX. Qualitative and quantitative differences in urinary arylsulfatase $A$ in different forms of MLD. Arch. Neurol., 24: 117 (1971).

37. Stumpf, D. A., Austin, J. H., Crocker, A. C., and LaFrance, M.: Mucopolysaccharidosis type VI (Maroteaux-Lamy syndrome). I. Sulfatase B deficiency in tissues. Amer. J. Dis. Child., 126: 747 (1973).

38. Stumpf, D. A., Neuwelt, E., Austin, J., and Kohler, P.: Metachromatic leukodystrophy (MLD). X. Immunological studies of the abnormal sulfatase A. Arch Neurol., 25: 427 (1971)

39. Van der Hagen, C. B., Børresen, A. L., Molne, K., Oftedal, G., Bjøro, K., and Berg, K.: Metachromatic leukodystrophy. I. Prenatal detection of arylsulphatase A deficiency. J. Clin. Genet., 4: 256 (1973).

40. Waddell, W. J.: A simple ultraviolet spectrophotometric method for the determination of protein. J. Lab. Clin. Med., 48: 311 (1956).

41. Wiesmann, U. N., Meier, C., Spycher, M. A., Schmid, W., Bischoff, A., Gantier, E., and Herschkowitz, N.: Prenatal metachromatic leukodystrophy. Helv. Ped. Acta, 30: 31 (1975).

42. Wolfe, H. J., and Pietra, G. G.: The visceral lesions of metachromatic leukodystrophy. Amer. J. Pathol., 44: 921 (1964).

43. Kalex Scientific Co., Manhasset, N. Y.

44. Type C 870 , Shandon Southern Instruments, Sewickley, Pa.

45. Sigma Chemical Co., St. Louis, Mo.

46. These studies were performed with the informed consent of the subjects.

47. This work was supported in part by Grant GM-06321 from the National Institutes of Health, by a grant from the Department of Health, Education and Welfare Maternal and Child Health Service (Project 417), and by a grant from the Medical Research Council of Canada, MA-5789. Dr. M. C. Rattazzi is the recipient of Research Career Development Award K04 GM 70638 from the National Institute of General Medical Sciences.

48. We thank Ms. E. Cooper and Ms. E. Villari for their valuable technical assistance. We also thank Dr. H. Jockin for the histochemical observations on fetal material; Dr. G. Thomas, Johns Hopkins University, Baltimore, for a sample of amniotic fluid from a fetus with MLD, and Dr. W. R. Bartholomew for providing anti-AS-A serum.

49. Requests for reprints should be addressed to: M. C. Rattazzi, M. D., Human Genetics, Children's Hospital, 86 Hodge Ave., Buffalo, N. Y. 14222 (USA).

50. Received for publication January $18,1977$.

51. Accepted for publication February 23, 1977. 